\title{
Geographical Applications of Performance Measures for Transit Network Directness
}

\author{
Young-Jae Lee, Ph.D. \\ Morgan State University \\ Jung Yoon Choi, Ph.D. Candidate \\ Jeong Whon Yu, Ph.D \\ Keechoo Choi, Ph.D. \\ Ajou University
}

\begin{abstract}
This research developed a geographical presentation method to show which areas of the city need to be improved in terms of the directness of transit service using two measures, Degree of Competitiveness and Degree of Circuity, which were developed in the first author's previous research. In this research, the directness of transit networks in five cities in Korea was analyzed and compared as an example and demonstrated geographically. The results show that although more populated cities are likely to provide more direct transit service than less populated cities, population density affects the transit network directness more. Also, this research showed that there is a strong relationship between transit network directness and transit ridership. As a result of this research, transit agencies can have a better visual understanding of their transit network directness and can improve transit network configuration where transit network directness is poor.
\end{abstract}

Key words: Transit network, performance measures, GIS, directness, circuity

\section{Introduction}

Transit network design is the foundation for efficient transit operation and planning. However, designing an efficient transit network is always difficult and requires considerable effort. To realistically improve a transit network, many transit agencies rely on evaluation measures. Measures to determine transit operation show how to diagnose current transit operations and make future planning more efficient. For these reasons, setting and developing measures are always important for transit agencies. Measures used for transit planning and operation are related to transit users, transit agencies, and society, as shown in Table 1 (TCRP 2003). 
TABLE 1.

\begin{tabular}{|c|c|c|c|}
\hline \multirow{4}{*}{$\begin{array}{l}\text { Customer } \\
\text { (Quality of } \\
\text { Service) }\end{array}$} & Travel Time & - Transit-auto travel time & - Transfer time \\
\hline & Availability & $\begin{array}{l}\text { - Service coverage } \\
\text { - Service denials }\end{array}$ & $\begin{array}{l}\text { - Frequency } \\
\text { - Hours of service }\end{array}$ \\
\hline & Service Delivery & $\begin{array}{l}\text { - Reliability } \\
\text { - Comfort }\end{array}$ & $\begin{array}{l}\text { - Passenger environment } \\
\text { - Customer satisfaction }\end{array}$ \\
\hline & Safety \& Security & $\begin{array}{l}\text { - Vehicle accident rate } \\
\text { - Passenger accident rate }\end{array}$ & $\begin{array}{l}\text { - Crime rate } \\
\text { - Percent of vehicles with } \\
\text { safety devices }\end{array}$ \\
\hline \multirow{3}{*}{ Agency } & $\begin{array}{l}\text { Maintenance \& } \\
\text { Construction }\end{array}$ & $\begin{array}{l}\text { - Road calls } \\
\text { - Fleet cleaning }\end{array}$ & $\begin{array}{l}\text { - Spare ratio } \\
\text { - Construction impact }\end{array}$ \\
\hline & Economic & $\begin{array}{l}\text { - Ridership } \\
\text { - Fleet maintenance performance }\end{array}$ & $\begin{array}{l}\text { - Cost efficiency } \\
\text { - Cost effectiveness }\end{array}$ \\
\hline & Transit Impact & $\begin{array}{l}\text { - Community economic impact } \\
\text { - Employment impact }\end{array}$ & $\begin{array}{l}\text { - Environmental impact } \\
\text { - Mobility }\end{array}$ \\
\hline \multirow{2}{*}{ Vehicle/Driver } & Capacity & $\begin{array}{l}\text { - Vehicle capacity } \\
\text { - Volume-to-capacity ratio }\end{array}$ & - Roadway capacity \\
\hline & Travel Time & - Delay & - System speed \\
\hline
\end{tabular}

Lee (2008) extensively researched the various kinds of measures for transit-auto travel time because they can show the competitiveness of a transit service, which eventually greatly affects ridership and revenue, as indicated in many studies (McGillivray 1970; Cambridge Systematics and Economic Development Research Group 1999; Fan and Machemehl 2004; Racca and Ratledge 2004). Lee's previous research discussed and developed comparative measures to diagnose current planning and operation in more efficient ways. Since travelers compare the available travel modes for their trips using travel times and costs, measures that show the relationship between auto travel time and transit travel time are very useful and show the competitiveness of a transit service. Measures that compare current transit networks and potential shortest travel-time transit networks also were developed. If the size of demand is large enough to provide high frequency for any route, this comparison reveals how much a transit network potentially can be improved. However, this previous research used only one hypothetical network and its data to demonstrate the methodology.

In this research, to analyze transit network directness efficiently, a geographical presentation method for transit network directness was developed based on the previously-developed measures to define competitiveness and directness of a transit network. Then, five major cities in Korea were analyzed using a geographical presentation method. GIS applications for transit performance analysis (Ramirez and Seneviratne 1996; Berkow 2009; Bertini and El-Geneidy 2003) have been gaining popularity and are believed to be very useful.

\section{Literature Review}

\section{Transit Network Configuration}

Transit network configuration is one of the most important components in determining the level of service for passengers and is the key to operational efficiency. Numerous stud- 
ies have been conducted using optimization techniques, including Lee (1998), Pattinak et al. (1998), and Lee and Vuchic (2005). Guiharire and Hao (2008) summarized the related studies extensively. However, optimizing transit network configuration always has been a difficult task for the transit industry, in part, due to the complexity of designing transit network configuration. Because of this complexity, most transit networks have been designed based on intuition and experience. Another difficulty is in changing a current network configuration. Although recent studies have shown how to optimize a transit network, it is difficult for transit agencies to complete changes all at once; it is recommended that modest changes in scheduling or the transit network be explored, rather than drastically changing the transit network configuration. Once a transit network is designed, user travel time cannot be improved drastically through other changes.

\section{Relationship between Routing and Scheduling}

Total transit travel time is computed as the sum of travel time components. Routing and scheduling are the major factors determining these components, although there are many considerations. Routing determines in-transit travel time and access/egress time (by station location) and also determines whether transfers are required for certain trips. Scheduling is closely related to waiting time and transfer time, if there is a transfer. Without scheduling information, average waiting time is half of the headway, assuming that passengers arrive uniformly at stations. Although waiting time with scheduling information does not have a definitive relationship with headway, unlike waiting time without scheduling information, it clearly moves in the same direction as headway.

Although the difficulty of coordinating routing and scheduling often results in their separate planning processes, routing and scheduling should be considered together. The relationship between routing and scheduling comes from the scheduling process. Scheduling is affected by many concerns, such as maximum policy headway and fleet size. However, the most important input for the scheduling process is demand size, because more frequencies usually are provided for the heavy-demand routes. To prevent overcrowding, frequency should be linearly related with demand. This means that demand for a certain route determines its frequency (Vuchic et al. 1976; Cedar and Israeli 1998).

Depending on routing, demand for a route is basically determined by (1) the number of riders picked up by the route, assuming fixed transit demand, and (2) in-vehicle travel time. The more efficient a transit route is, the larger the share transit can have from the general demand for the trip. For these reasons, although routing and scheduling are separate and different processes, routing affects and generally determines scheduling.

Under fixed transit demand, a route collects more riders if it is circuitous, resulting in higher frequency and shorter headway. However, there is a trade-off with circuitous routing-even though it can provide shorter waiting time due to a shorter headway, it requires longer in-transit travel. Increasing directness results in shorter in-transit travel time under the assumption of a single mode, but it requires more routes and lower frequency for each route due to less demand for each route. Lower frequency results in longer headway and, eventually, longer waiting time. 


\section{Transportation Network Circuity}

Previous research defined and analyzed the transportation network circuity by means of geography. Circuity was defined as the ratio of the shortest network distance over Euclidean distance between origin and destination (Barthlemy 2011). Newell (1980) found that the average circuity on a road network was around 1.2, and Ballou et al. (2002) estimated the travel distance through the several countries. However, there has been no research to compare auto network circuity and transit network circuity based on a given road network.

\section{Demand Size and Circuity of the Transit Network}

The overall shape of transit network configuration typically can be classified in three ways (Lee 2006): directly-connected networks with a larger number of routes, networks with a smaller number of routes that are circuitous, and networks that require transfers due to fewer directly-connected routes. Demand size is a primary consideration in determining the type of transit network. When demand is low, providing many routes with direct connection is not efficient because the frequency of each route would be low, resulting in longer waiting times. Direct connection is a better choice when demand is sufficient, because networks still can provide short headway with many direct routes.

Transit networks with transfers share characteristics with transit networks that have circuitous routes. Frequencies of those networks are higher than those of directly-connected networks due to the smaller number of routes, but in-vehicle travel time is still short due to the direct connection. However, transfer time exists in total travel time. If a network has fewer circuitous routes, waiting time would be shorter due to the higher frequency, but in-vehicle travel time would be longer due to circuitous routing.

\section{Transit Score}

The website www.walkscore.com provides information related to walk scores (walkability) and transit scores (transit friendliness) at neighborhood levels (Walk Score 2014). According to the site, a transit score is a patented measure of how well a location is served by public transit and is based on data released in a standard format by public transit agencies. To calculate a transit score, a "usefulness" value is assigned to nearby transit routes based on frequency, type of route (rail, bus, etc.), and distance to the nearest stop on the route. The "usefulness" of all nearby routes is summed and normalized to a score of $0-100$. Although this site rates accessibility to transit service, it does not address how competitive transit service is in terms of travel time versus auto travel time. A transit score may be related to access time and waiting time, but not to the in-vehicle travel time to a destination, which is usually the largest part of total transit travel time.

\section{Methodology}

\section{Measures for Transit Network Directness}

In Lee's previous research (2008), two comparative measures were developed-Degree of Competitiveness (DOCO) and Degree of Circuity (DOCI) - which compare the performance of auto and transit and evaluate potential transit network performance. The main comparison in this research is travel time. DOCO is a comparison between auto and transit travel times and shows how transit service is competitive with auto for each ori- 
gin-destination trip. DOCI measures how much the transit service or network configuration can be improved; in general, if transit ridership increases, the optimality of the transit network becomes higher with more direct connections between origin-destination pairs (Lee 1998). DOCl indicates how circuitous a current transit network is compared to a hypothetical transit network with the possible shortest connections, which provides the shortest in-vehicle transit travel time.

Although it is simple to estimate auto travel time, estimating transit travel time is more complex because of its various travel time components. Transit users generally consider travel time as total transit travel time and in-vehicle transit travel time. Total transit travel time includes waiting time and complete door-to-door travel time (or station-to-station travel time for a simpler computation). Waiting time can be determined by many other considerations in addition to demand size. When a headway is long and schedule information is provided, waiting time may not be estimated from headway and frequency. As a result, travel time can be distorted by the length of waiting time when the transit network is evaluated. In-vehicle transit travel time, which excludes waiting time, is transit travel time after boarding. This measure excludes waiting time, which is stochastic among all the components of travel times, so it could represent the transit network configuration better than total transit travel time. However, in-transit travel time does not include the relationship between routing and scheduling and may not represent the overall performance of the transit system. (Access and egress times are also part of a transit trip and total transit travel time, but they are excluded from this paper for simplicity.)

Auto travel time and transit travel time are compared as the Degree of Competitiveness. DOCO is a measure designed to show how much additional travel time the transit network requires when compared to auto travel time. If transit travel time is identical to auto travel time, its DOCO is zero.

As stated earlier, there are two types of competitiveness that can be considered with the two different kinds of transit travel time-Total Travel Time Degree of Competitiveness (TTTDOCO) and In-Vehicle Travel Time Degree of Competitiveness (ITTDOCO). TTTDOCO compares door-to-door travel times of auto and transit and shows how competitive the transit system is. ITTDOCO compares the in-vehicle travel time of auto and transit; since waiting time is not included in the comparison and auto travel follows the shortest paths, ITTDOCO shows how direct the transit network configuration is. Equations 1 and 2 show the TTTDOCO and ITTDOCO, respectively, for an individual user or a certain origin-destination.

$$
\begin{aligned}
& \text { Individual TTTDOCO [\%] }=100 \cdot \frac{\Delta t_{i j}^{T 1}+t_{i j}^{t}+p_{i j}}{\min t_{i j}^{a}} \\
& \text { Individual ITTDOCO [\%] }=100 \cdot \frac{\Delta t_{i j}^{i 1}+t_{i j}^{t}+p_{i j}}{\min t_{i j}^{a}} \\
& \text { Where, }
\end{aligned}
$$

$\Delta t_{i j}^{T 1}=$ additional total travel time (difference between real total travel time of transit and shortest travel time of auto) from $i$ to $j$ 
$\Delta t_{i j}^{i 1}=$ additional in-vehicle travel time (difference between real in-vehicle travel time of transit and shortest travel time of auto) from $i$ to $j$

$t_{i j}^{t}=$ transfer time from $i$ to $j$

$p_{i j}=$ transfer penalty from $i$ to $j$

$\min t_{i j}^{a}=$ auto shortest path travel time from $i$ to $j$

$\mathrm{DOCl}$ shows how much additional travel time is required by the current transit network compared to the directly-connected hypothetical transit network. This is due to the indirect connection of the current transit network. There are two types of DOCl. Total Travel Time Degree of Circuity (TTTDOCI) compares the real door-to-door (precisely, station-to-station in this example) travel times of the current transit system and the potential minimum transit travel time. This assumes that the potential minimum transit travel time is estimated with no waiting time and the shortest connected in-vehicle travel time. TTTDOCI shows how much the transit system ultimately can be improved. In-vehicle Travel Time Degree of Circuity (ITTDOCI) compares the current in-vehicle travel time of transit and potential shortest in-vehicle travel time. Since potential shortest in-travel time comes from the directly-connected transit network and waiting time is not included in the comparison, ITTDOCI shows how direct the transit network configuration is. Equations 3 and 4 show the TTTDOCI and ITTDOCI, respectively, for an individual user or a certain origin-destination.

$$
\begin{aligned}
& \text { Individual TTTDOCI [\%] }=100 \cdot \frac{\Delta t_{i j}^{T 2}+t_{i j}^{t}+p_{i j}}{\min t_{i j}^{i}} \\
& \text { Individual ITTDOCI [\%] }=100 \cdot \frac{\Delta t_{i j}^{i 2}+t_{i j}^{t}+p_{i j}}{\min t_{i j}^{i}}
\end{aligned}
$$

Where,

$\Delta t_{i j}^{T 2}=$ additional total travel time (difference between real total travel time of transit and total travel time of potential transit shortest path) from $i$ to $j$

$\Delta t_{i j}^{i 2}=$ additional in-vehicle travel time (difference between real in-vehicle travel time of transit and in-vehicle travel time of potential transit shortest path) from $i$ to $j$

$t_{i j}^{t}=$ transfer time from $i$ to $j$

$p_{i j}=$ transfer penalty from $i$ to $j$

$t_{i j}^{i}=$ in-vehicle travel time of potential transit shortest path from $i$ to $j$

Two DOCOs and two DOCls can be presented for each origin-destination trip, as shown in the equations and for the whole network.

For estimating measures for the entire network, simple average and weighted average can be used based on different ways to consider demand. Simple average does not consider 
zone-to-zone demand. Without consideration of the demand size, these measures represent competitiveness or circuity of the transit network with the same weight for each origin-destination. Equations 5 and 6 show two simple DOCO for the total travel time and in-vehicle travel time. Equations 7 and 8 show simple DOCl. In the equations, $n(n-1)$ is used instead of $n^{2}$ as the denominator for the simple average because it is assumed that there are no intra-zonal trips.

Simple average TTTDOCO [\%] $=\sum_{i=1}^{n} \sum_{j=1}^{n} \frac{\text { individual }(\text { TTTDOCO })_{i j}}{n(n-1)}$

Simple average ITTDOCO [\%] $=\sum_{i=1}^{n} \sum_{j=1}^{n} \frac{\text { individual }(\text { ITTDOCO })_{i j}}{n(n-1)}$

Simple average TTTDOCI [\%] $=\sum_{i=1}^{n} \sum_{j=1}^{n} \frac{\text { individual }(\text { TTTDOCI })_{i j}}{n(n-1)}$

Simple average ITTDOCI [\%] $=\sum_{i=1}^{n} \sum_{j=1}^{n} \frac{\text { individual }(\text { ITTDOCI })_{i j}}{n(n-1)}$

Weighted average considers each zone-to-zone demand size. The weighted average shows how efficiently the transit network is designed to meet the demand and how well the transit network provides better service to an origin-destination with higher demand. This is shown in Equations 9 through 12.

Weighted average TTTDOCO [\%] $=\frac{\sum_{i=1}^{n} \sum_{j=1}^{n} D_{i j} \cdot \text { individual }(\text { ITTDOCO })_{i j}}{\sum_{i=1}^{n} \sum_{j=1}^{n} D_{i j}}$

Weighted average ITTDOCO [\%] $=\frac{\sum_{i=1}^{n} \sum_{j=1}^{n} D_{i j} \cdot \text { individual }(\text { TTTDOCI })_{i j}}{\sum_{i=1}^{n} \sum_{j=1}^{n} D_{i j}}$

Weighted average TTTDOCI [\%] $=\frac{\sum_{i=1}^{n} \sum_{j=1}^{n} D_{i j} \cdot \text { individual }(\text { ITTDOCI })_{i j}}{\sum_{i=1}^{n} \sum_{j=1}^{n} D_{i j}}$

Weighted average ITTDOC $[\%]=100 \cdot \frac{\sum_{i=1}^{n} \sum_{j=1}^{n} D_{i j} \cdot \text { individual }(\text { TTTDOCO })_{i j}}{\sum_{i=1}^{n} \sum_{j=1}^{n} D_{i j}}$

Where $n=$ number of zones and $D_{i j}=$ demand from zone $i$ to zone $j$. 


\section{Travel Time Estimation for Auto and Transit}

The inputs defined in Equations 1-12 are necessary to estimate the DOCO and DOCl. Those inputs-demand size, link travel time, and transfer time-can be obtained easily. However, the real travel time of auto and transit and the potential shortest travel time of transit should be found and computed through route choice algorithms.

Auto travel time assumes that users find the shortest auto travel paths. With this assumption, auto travel time can be estimated using the shortest path algorithm. This theory is well-known and has been developed by many scholars, including Moore (1957), Dijkstra (1959), and Dantzig (1966). This shortest path algorithm provides the shortest path with a given fixed travel time. In reality, link travel time varies with traffic volume, and this shortest path algorithm may not be adequate; however, estimating real travel time with real travel demand is very complicated and difficult.

To estimate the transit travel time in this research, Optimal Strategy by Spiess and Florian (1989) was chosen as the transit route choice model, which is popularly used for transit assignment.

As discussed previously, comparison of an auto network and a transit network may not successfully show the effectiveness of the current transit network because transit link travel time and auto link travel time are different. Although this comparison can show how competitive a transit service is, the comparison does not show how much the current transit system can be improved. To determine how much the current transit network can be improved, comparison with the potential transit shortest paths may be more adequate. The potential transit shortest path can be found by using the auto shortest path algorithm with transit link travel time instead of auto link travel time. This is the hypothetical transit path, assuming that transit does not have fixed routes and can go anywhere with the shortest path.

\section{Geographical Presentation of Transit Network Directness}

From each zone, the simple average and the weighted average of measures to all other zones can be presented geographically and can provide a good geographical guideline of which areas need to be improved in terms of the directness of the transit service.

\section{Data and Modeling}

This analysis uses origin-destination data and road network data from the Korea Transportation Database (KTDB). However, KTDB's Transportation Analysis Zone (TAZ) is too large for analyzing the transit network system, so a smaller-size zone was created for this study based on census data. Transit operation data, including average speed and average headway of all available public transportation including metro rail system, regional express bus, regular bus, and small local bus systems, came from databases provided by the local governments, Korea Railroad (KoRail), Seoul Metropolitan Rapid Transit Corporation, and local bus companies of the analyzed cities. A transfer penalty was assumed as $20 \%$ of transfer waiting time, which is a conventional default value for analysis in Korea as well as a default value at TransCad. Modeling and computation of travel times were done using TransCAD. 


\section{Example and Analysis}

Five cities in Korea-Seoul, Busan, Suwon, Seongnam, and Uijeongbu-were chosen for the analysis. Seoul is the largest city in Korea, and Busan is the second largest. Suwon, Seongnam, and Uijeongbu are mid-size cities near metropolitan Seoul. City characteristics are shown is in Table 2, and zones and transit networks for the analysis are shown in Figure 1.

TABLE 2.

Characteristics of Cities in Analysis (2011)

\begin{tabular}{|l|r|r|r|r|r|}
\hline \multicolumn{1}{|c|}{ Characteristic } & Seoul & Busan & Suwon & Seongnam & Uijeongbu \\
\hline Population (million prs) & 10.25 & 3.55 & 1.09 & 0.98 & 0.43 \\
\hline Area $\left(\mathrm{Km}^{2}\right)$ & 605.25 & 765.64 & 121.01 & 141.74 & 81.59 \\
\hline Population density (prs/Km ${ }^{2}$ ) & 16,935 & 4,637 & 9,008 & 6,914 & 5,270 \\
\hline Bus passenger per day (million prs/day) & 5.58 & 1.53 & 0.85 & 0.55 & 0.21 \\
\hline Subway passenger per day (million prs/day) & 6.35 & 0.96 & 0.24 & 0.23 & 0.07 \\
\hline Transit demand density (prs/Km $\left.{ }^{2}\right)$ & 19,710 & 3,252 & 9,008 & 5,503 & 3,432 \\
\hline Transit demand/population & 1.16 & 0.70 & 1.00 & 0.80 & 0.65 \\
\hline Number of zones & 2,088 & 1,070 & 682 & 448 & 160 \\
\hline Number of bus routes & 435 & 271 & 114 & 56 & 72 \\
\hline Number of subway routes & 9 & 4 & 1 & 2 & 2 \\
\hline
\end{tabular}




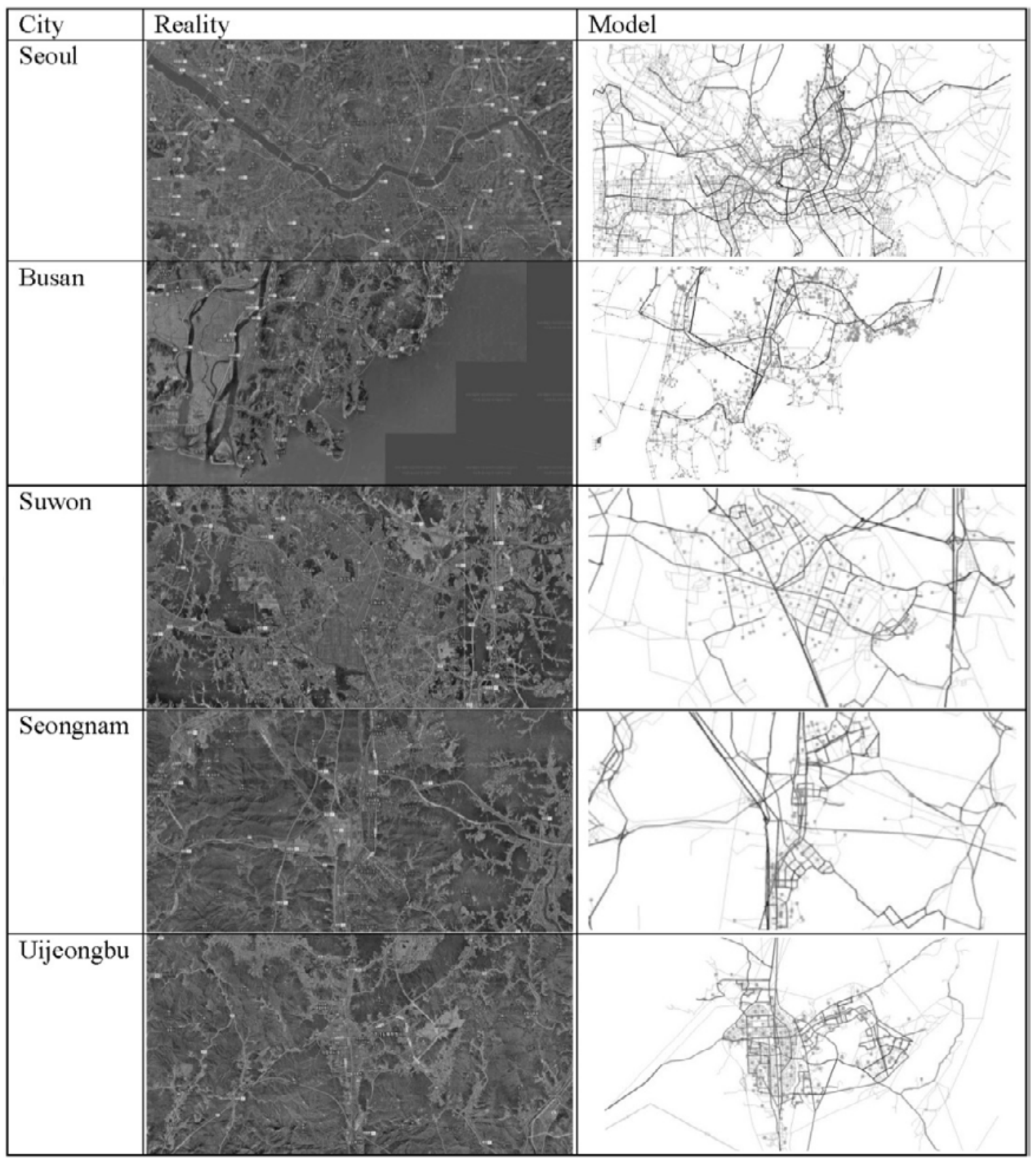

FIGURE 1. Modeling zones and transit networks of cities in analysis

Table 3 shows the results of the computed measures for the five cities. Seoul's values are the average of its 2,088 zones, and Busan's values are the average of its 1,070 zones. Each zone's value is the average of the values from that zone (origin) to all other zones (destinations). 
TABLE 3.

Summary of Transit

Directness Measures

\begin{tabular}{|c|c|c|c|c|c|c|}
\hline Measure & Simple & Weighted & Simple & Weighted & Simple & Weighted \\
\hline & \multicolumn{2}{|c|}{ Seoul } & \multicolumn{2}{|c|}{ Busan } & \multicolumn{2}{|c|}{ Suwon } \\
\hline TTTDOCO & $197 \%$ & $186 \%$ & $268 \%$ & $267 \%$ & $221 \%$ & $210 \%$ \\
\hline ITTDOCO & $145 \%$ & $136 \%$ & $202 \%$ & $199 \%$ & $162 \%$ & $155 \%$ \\
\hline TTTDOCI & $110 \%$ & $101 \%$ & $152 \%$ & $150 \%$ & $125 \%$ & $112 \%$ \\
\hline \multirow[t]{2}{*}{ ITTDOCI } & $75 \%$ & $66 \%$ & $103 \%$ & $99 \%$ & $86 \%$ & $74 \%$ \\
\hline & \multicolumn{2}{|c|}{ Seongnam } & \multicolumn{2}{|c|}{ Uijeongbu } & & \\
\hline TTTDOCO & $290 \%$ & $278 \%$ & $336 \%$ & $333 \%$ & & \\
\hline ITTDOCO & $213 \%$ & $200 \%$ & $254 \%$ & $252 \%$ & & \\
\hline TTTDOCI & $163 \%$ & $147 \%$ & $187 \%$ & $182 \%$ & & \\
\hline ITTDOCI & $112 \%$ & $97 \%$ & $128 \%$ & $126 \%$ & & \\
\hline
\end{tabular}

TTTDOCO = Total Travel Time Degree of Competitiveness, ITTDOCO = In-vehicle Travel Time Degree of Competitiveness, $T T T D O C I=$ Total Travel Time Degree of Circuity, ITTDOCI = In-vehicle Travel Time Degree of Circuity

Assuming that transit networks are not direct, $\mathrm{DOCl}$ is always more than $0 \%$. Assuming that auto travel is faster than transit travel because of shorter access and egress time and no waiting time, DOCO is always higher than DOCl. Also, a transit route with higher demand has a better chance of being direct, and weighted averages are always lower than simple averages. Table 3 shows that the results meet all of these assumptions as well as general common sense.

In good transit network design, weighted measures should be lower than simple measures because heavily-demanded trips are designed to be more direct. In Table 3, it is noticeable that the difference between simple measures and weighted measures for Busan and Uijeongbu are minimal compared to the other cities, meaning that transit networks in Busan and Uijeongbu are not properly designed for heavy demand.

In Table 3, the average additional travel time by transit (weighted) in Seoul is $186 \%$ more than auto travel time and the average transit travel time with the current Seoul transit system is $66 \%$ more than that of a potential ideal transit network. The measures for Seoul are lower than those for the other cities because Seoul is highest in population density and has more transit demand; as a result, Seoul can provide a more direct transit network than the other smaller cities. If a transit network is designed properly, a city with more demand is likely to have a more direct transit network. However, that may not occur in all cities. As shown in Table 4, although Busan is the second largest city in population, because its area is largest, its population density is lowest (\#5). However, because of its relatively high ranking in transit network directness (\#3), Busan's ratio for transit demand/ population is \#4, which is better than Uijeongbu's, although Busan's transit demand density is still the lowest (\#5). 
TABLE 4.

Rankings of Cities for Analysis Measures (2011)

\begin{tabular}{|l|c|c|c|c|c|}
\hline & Seoul & Busan & Suwon & Seongnam & Uijeongbu \\
\hline Population & 1 & 2 & 3 & 4 & 5 \\
\hline Area & 2 & 1 & 4 & 3 & 5 \\
\hline Population density & 1 & 5 & 2 & 3 & 4 \\
\hline Transit demand density & 1 & 5 & 2 & 3 & 4 \\
\hline Transit demand/population & 1 & 4 & 2 & 3 & 5 \\
\hline Number of bus route & 1 & 2 & 3 & 5 & 4 \\
\hline Transit directness measures & 1 & $3 / 4$ & 2 & $4 / 3$ & 5 \\
\hline
\end{tabular}

Although Uijeongbu is the smallest of the five cities in terms of population, because of its small area, population density ranks fourth and the number of bus routes is relatively high for the area size and population size (especially compared to Seongnam). However, all of Uijeongbu's measures are worse than all the other cities', including Seongnam's, meaning that the transit network for Uijeongbu is unnecessarily indirect compared to other cities. In addition to Busan, all the other cities show a good correlation among population density, transit demand density, and transit network directness, which shows that transit network directness can be a very strong measure for transit ridership.

In Figure 2, the averages in Table 3 were broken down to show the composition of the zones for each additional travel time category, indicating the percentage of zones with relatively competitive and direct service and the percentage of zones with relatively indirect and uncompetitive service. Figure 2 shows that all cities have proper compositions. A city that has a lower average value of measures, such as Seoul, has more zones of lower values of measures, and a city that has a higher average value of measures, such as Uijeongbu, has more zones of higher value of measures. Figures 3 and 4 show the spatial distribution of measures for each city. These figures clearly show which zones have circuitous transit service visually. As expected, central business district (CBD) areas enjoy more direct service to other zones than do outside areas. These figures provide a good geographical guideline of which areas need to be improved in terms of transit service. 
FIGURE 2.

Frequencies of zones as percentages for transit directness measures

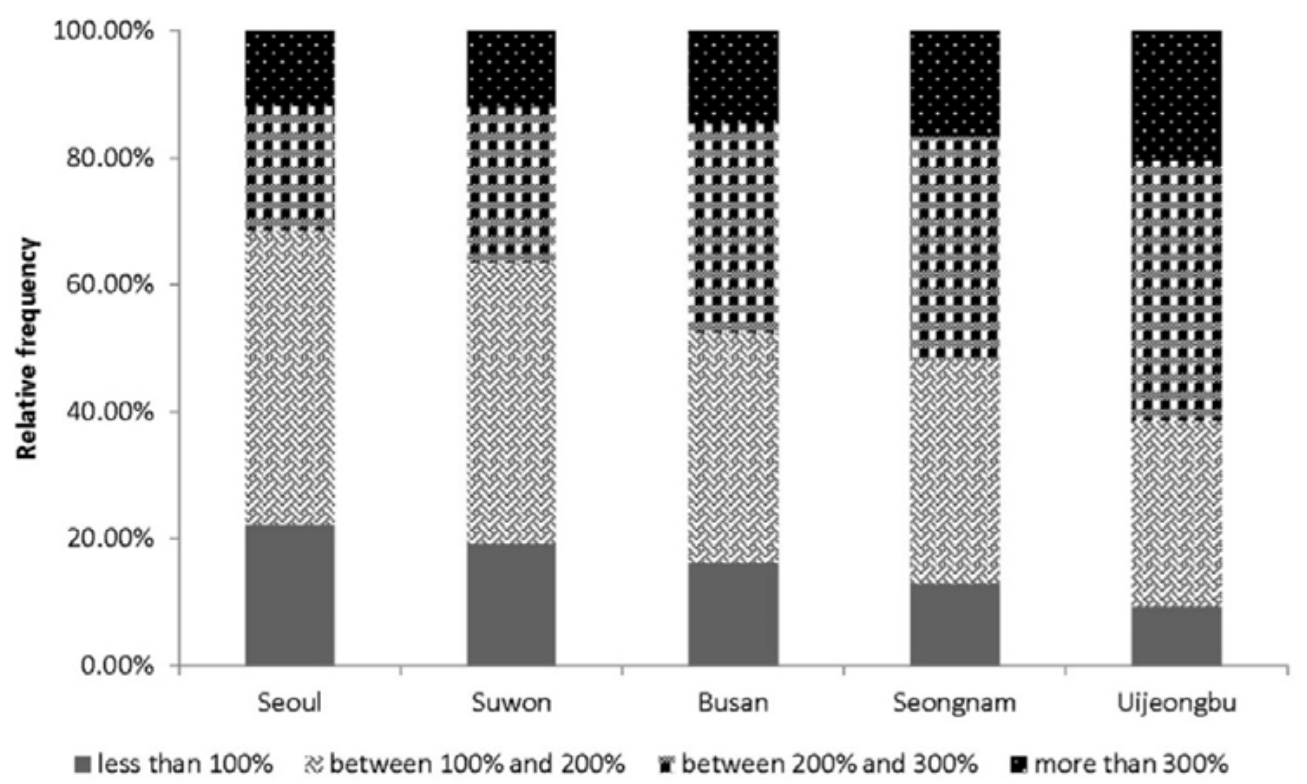

(a) Simple Average TTTDOCO

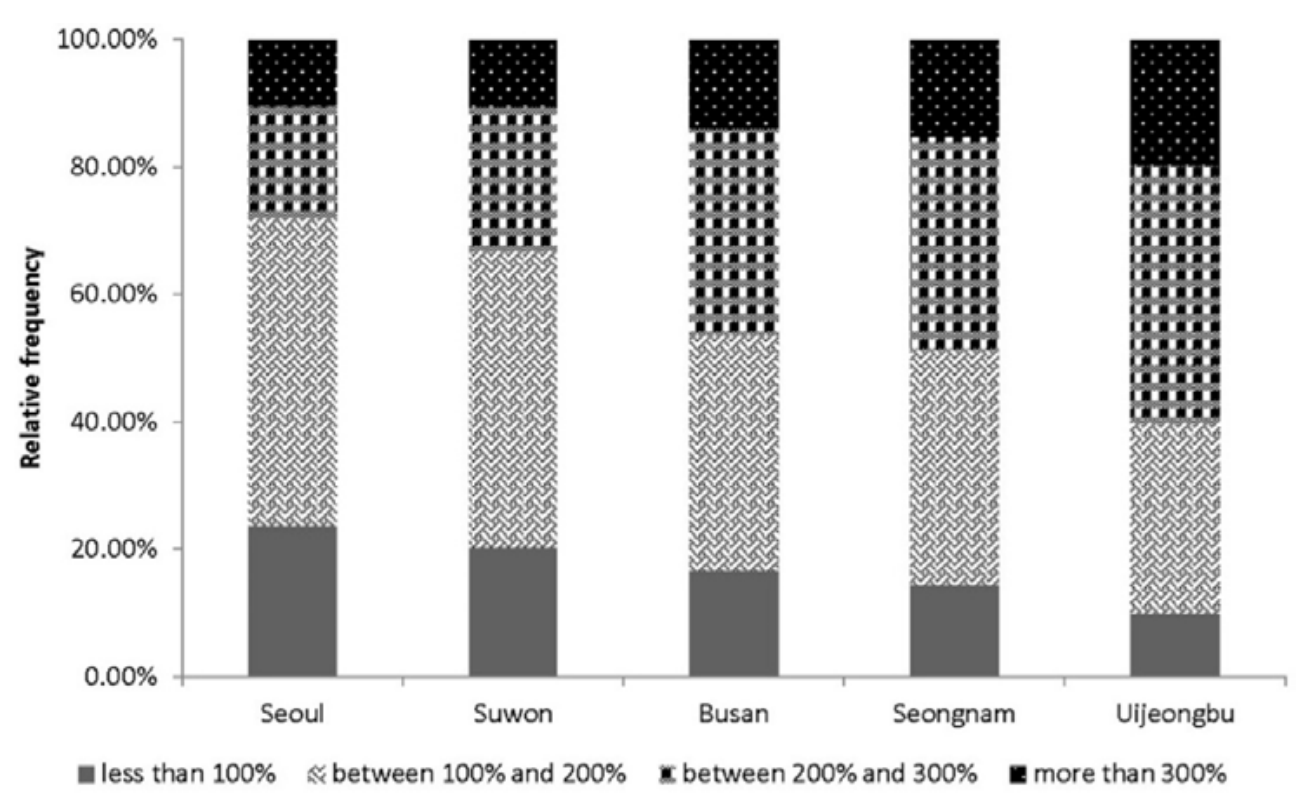

(b) Weighted Average TTTDOCO 
FIGURE 2. (cont'd.)

Frequencies of zones as

percentages for transit

directness measures

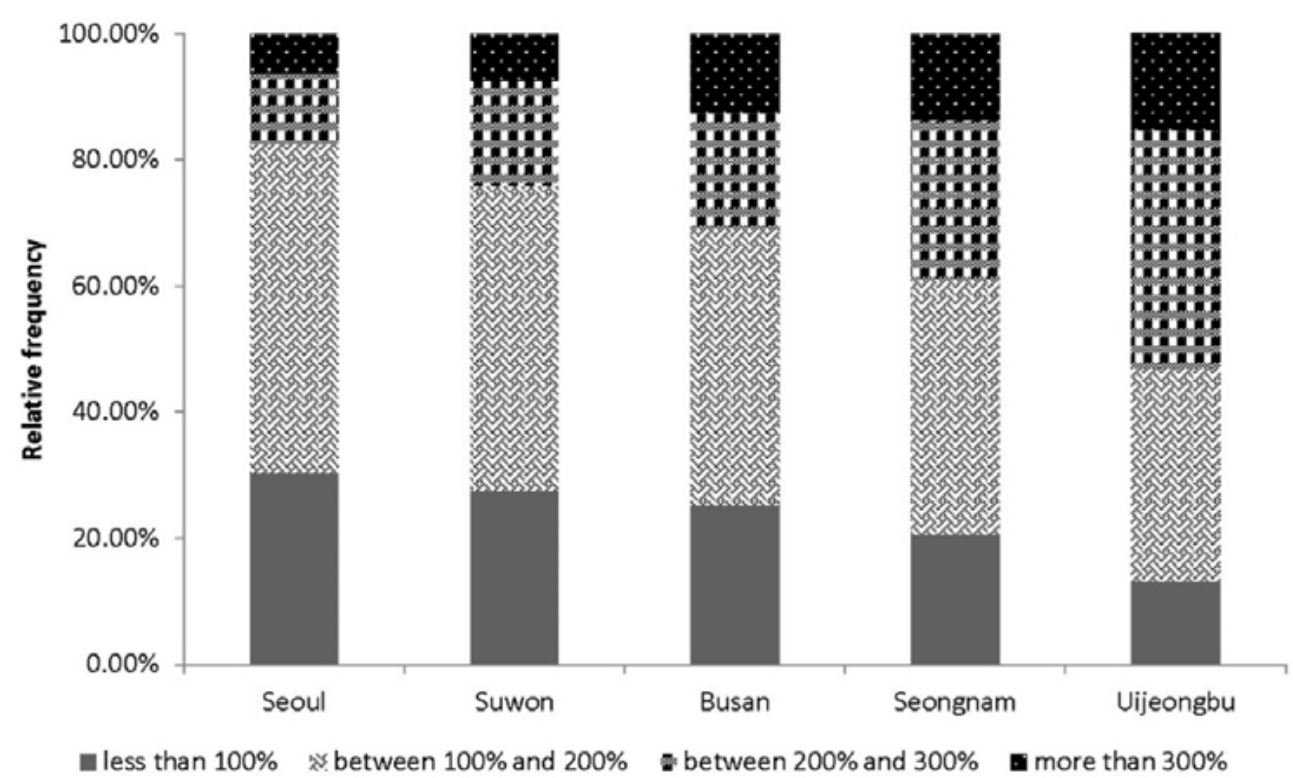

(c) Simple Average ITTDOCO

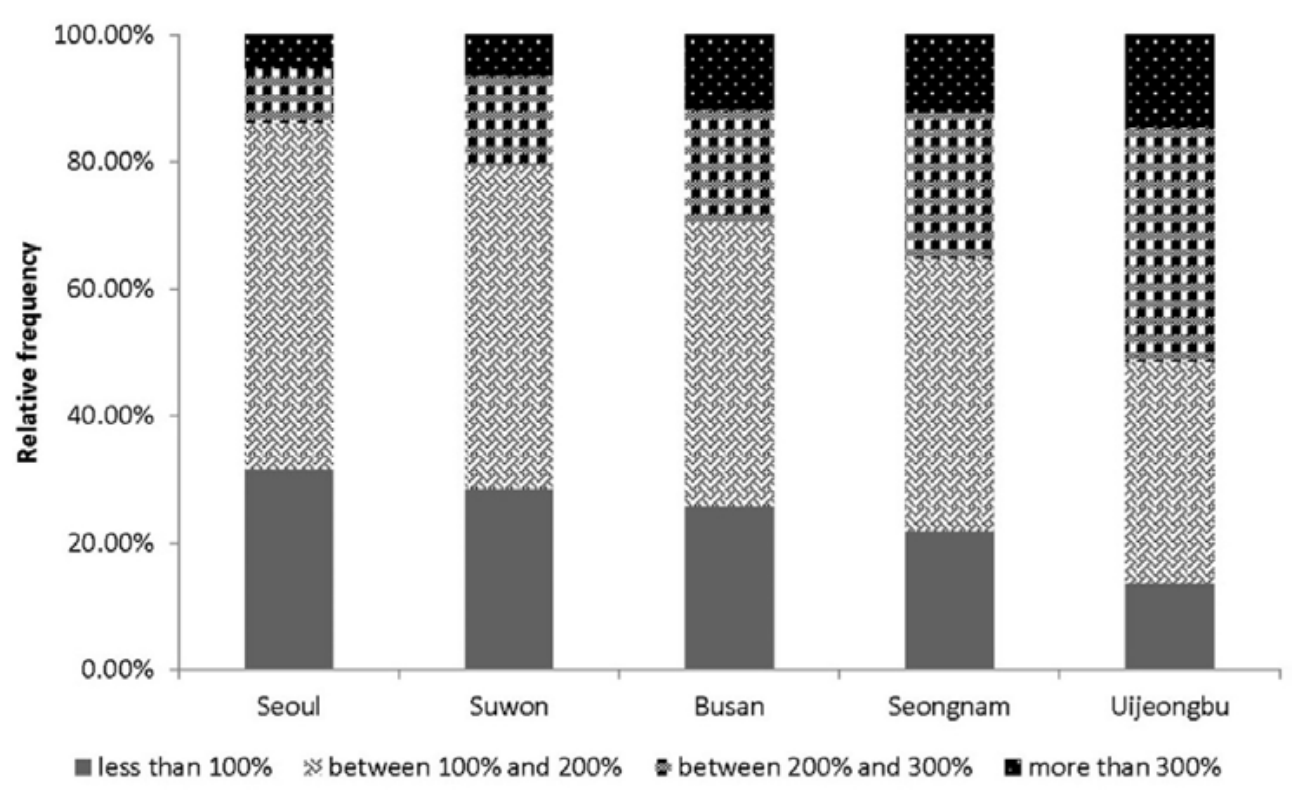

(d) Weighted Average ITTDOCO 
FIGURE 2. (cont'd.)

Frequencies of zones as

percentages for transit

directness measures
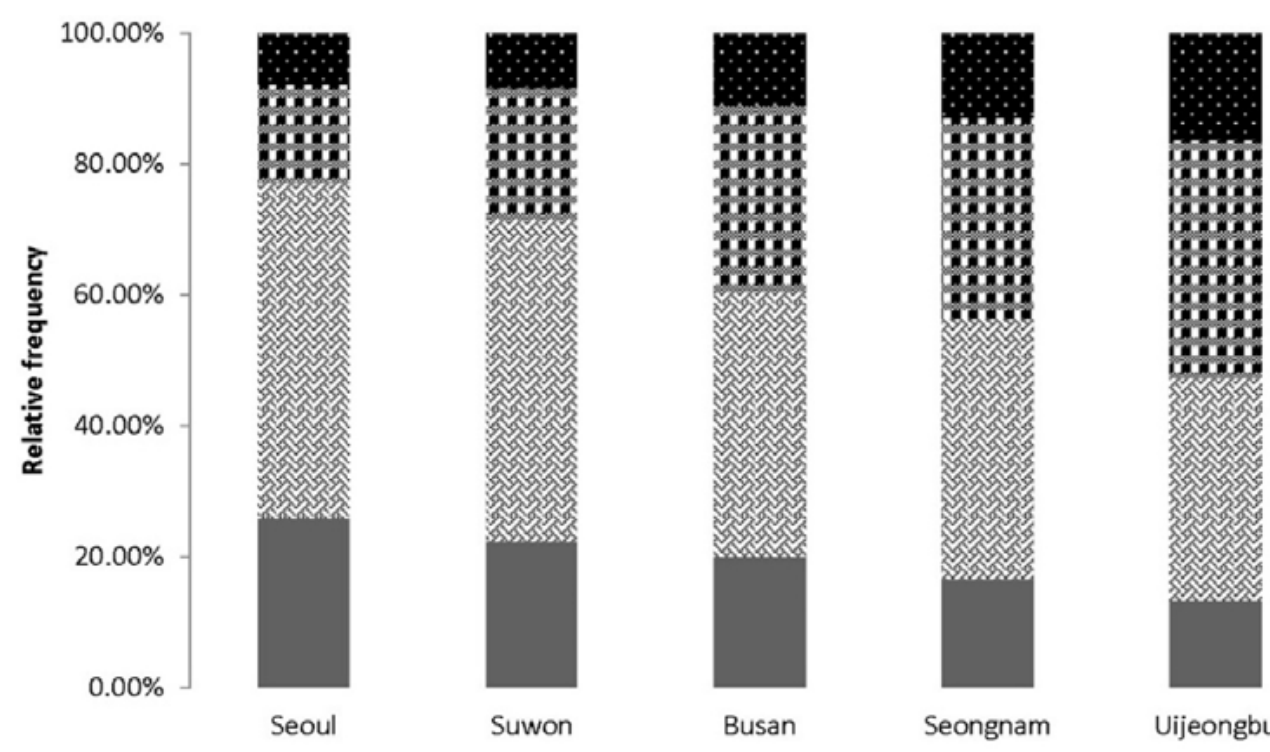

less than $100 \%$ between $100 \%$ and $200 \%$

Busan

Seongnam

Uijeongbu

(e) Simple Average TTTDOCI

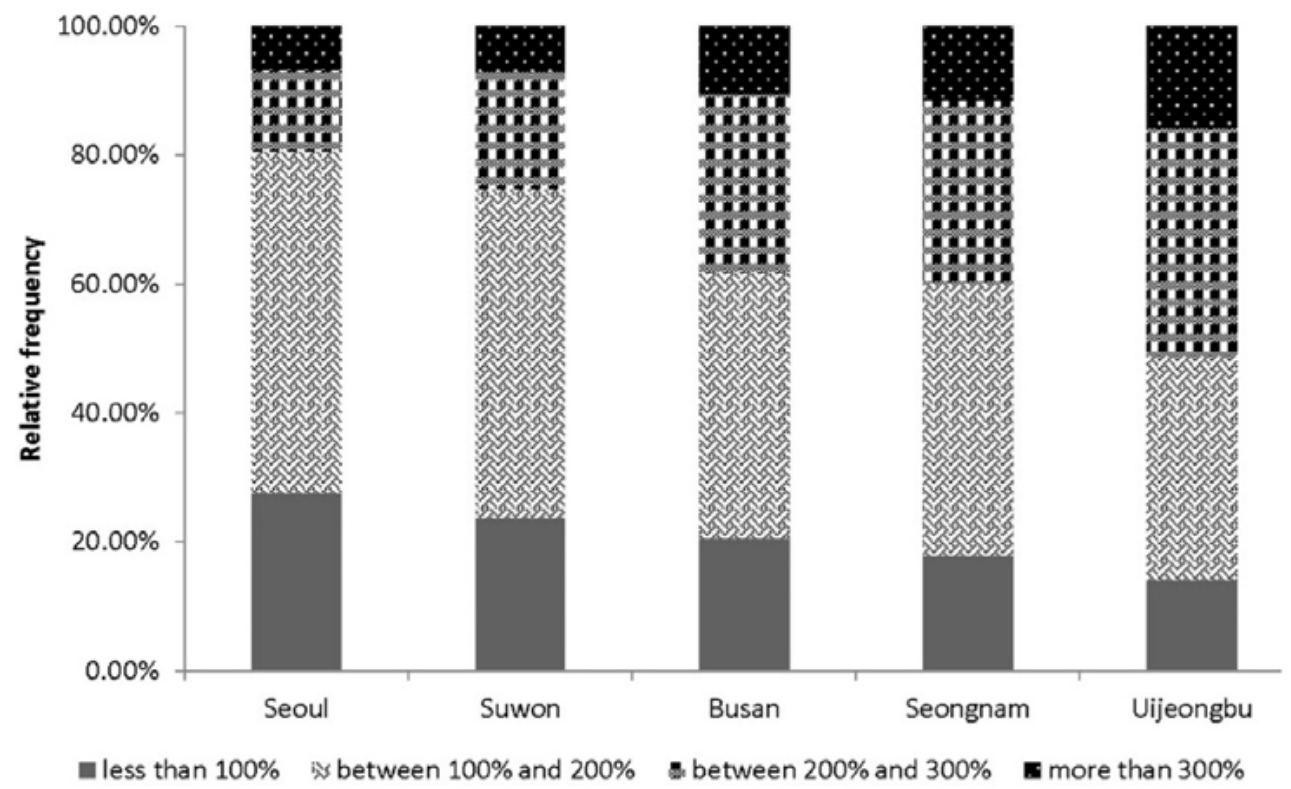

(f) Weighted Average TTTDOCI 
FIGURE 2. (cont'd.)

Frequencies of zones as

percentages for transit

directness measures

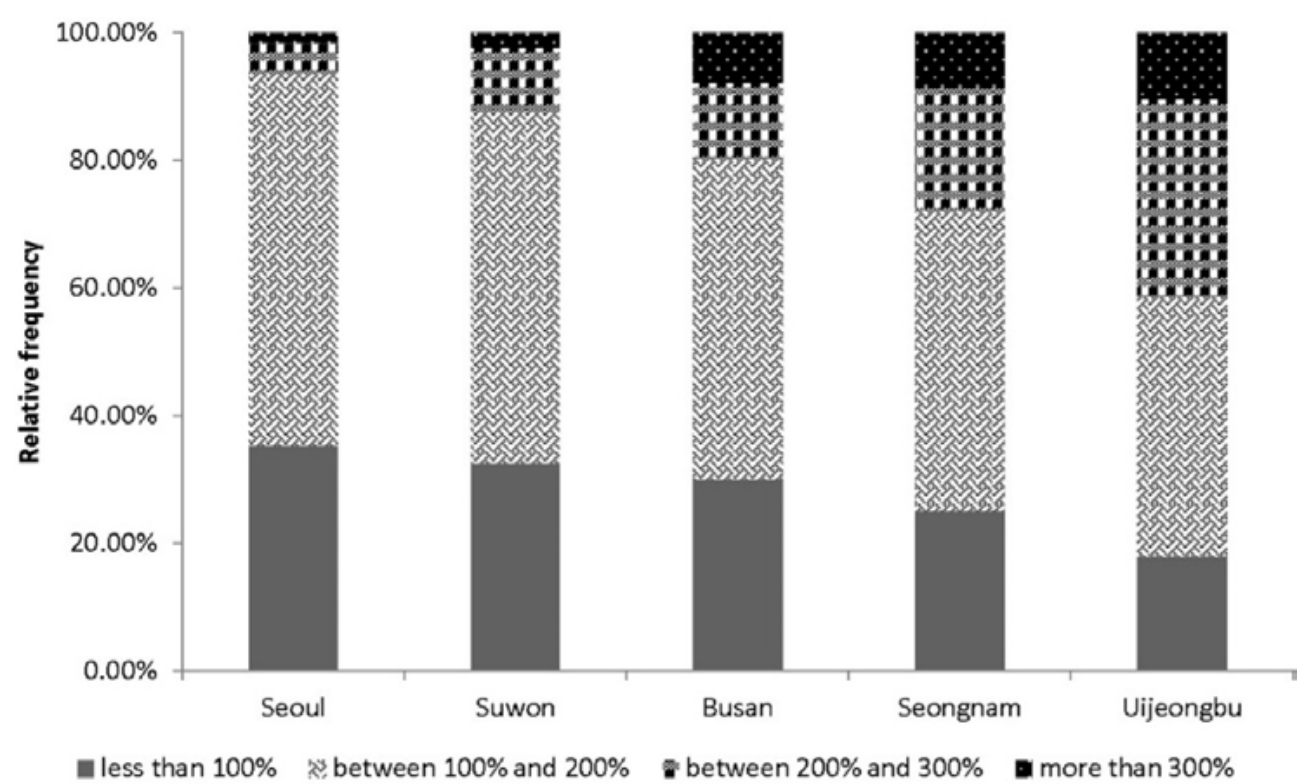

(g) Simple Average ITTDOCI

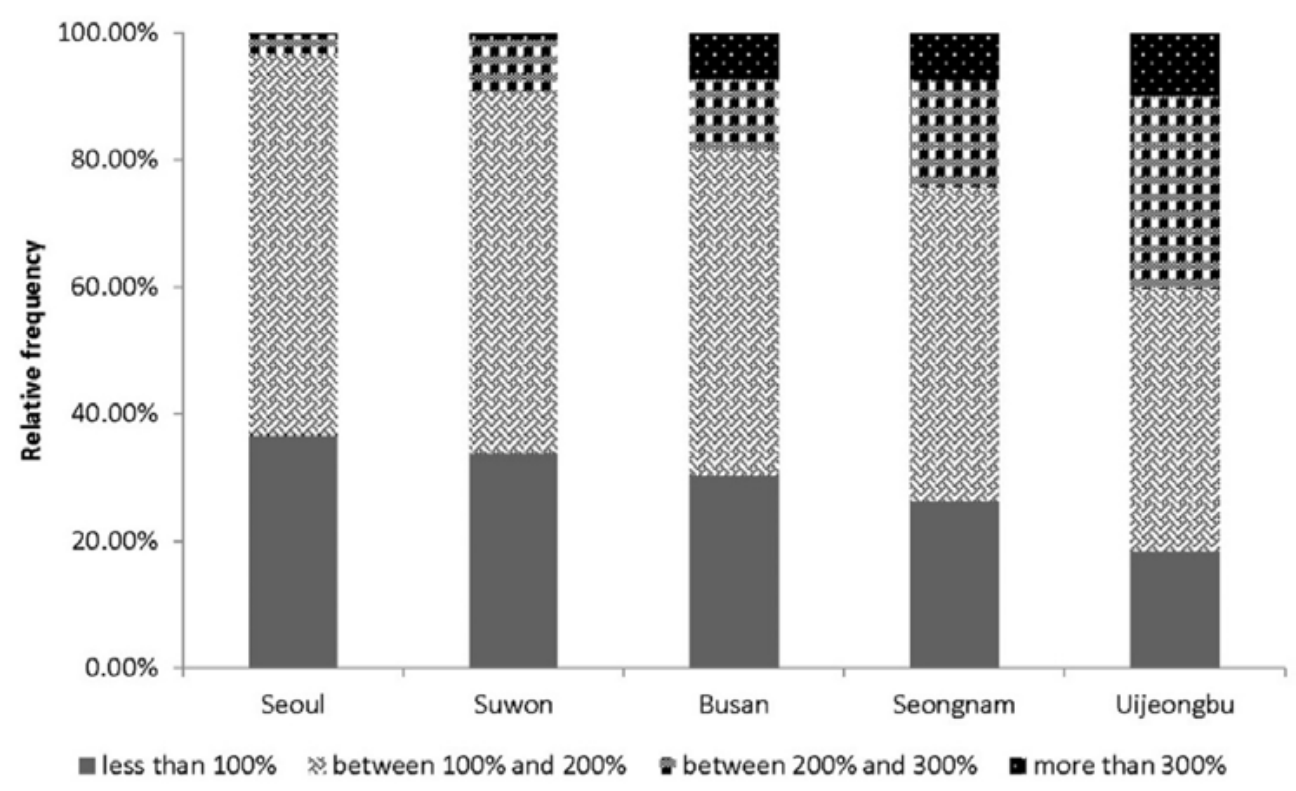

(h) Weighted Average ITTDOCI 


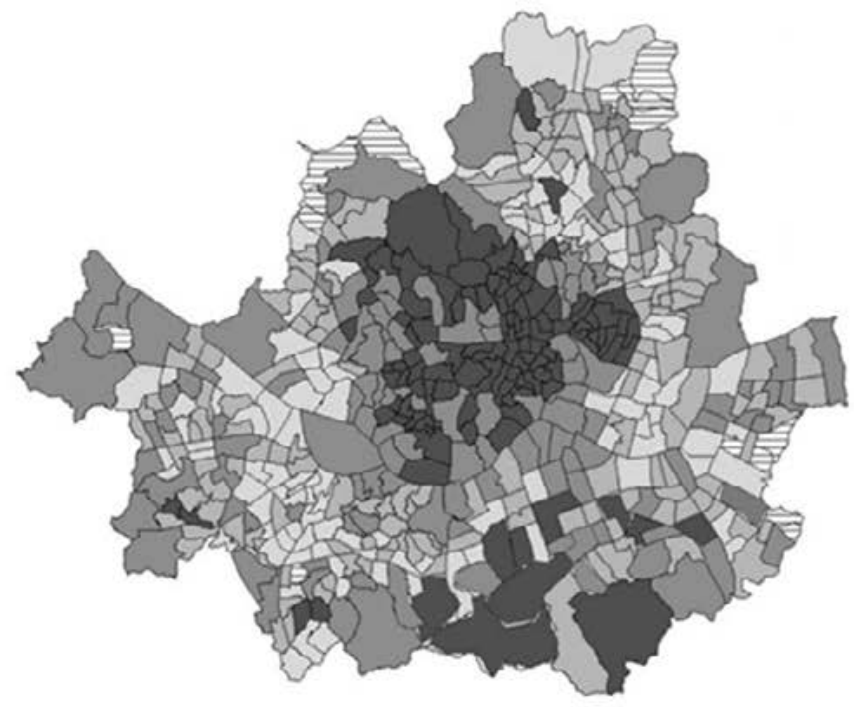

(a) Seoul

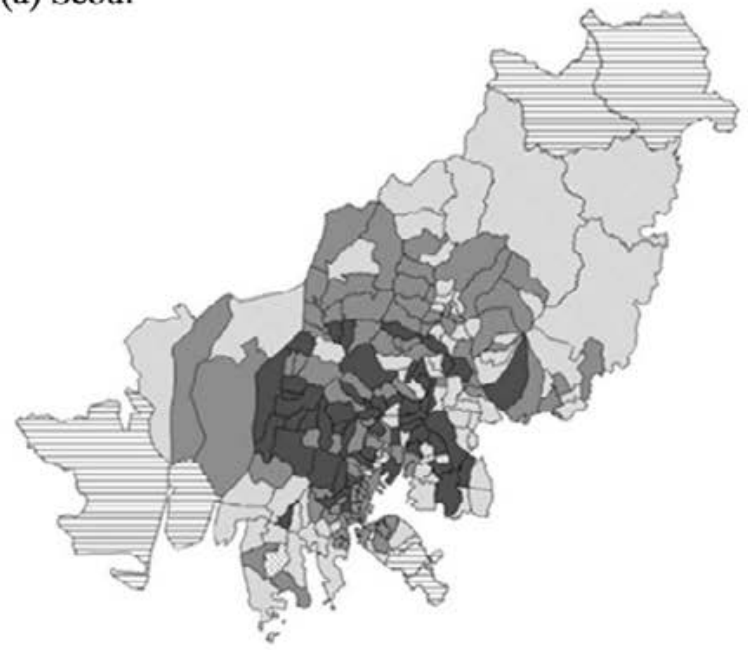

(b) Busan

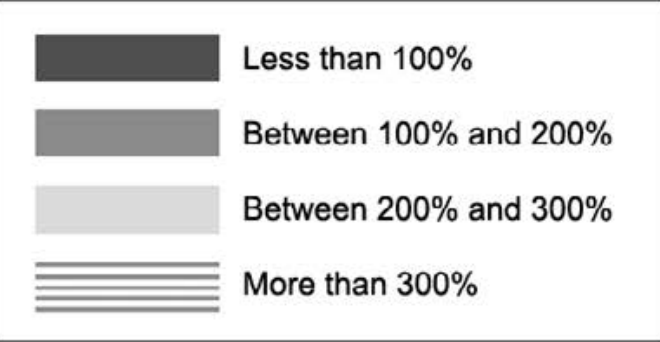

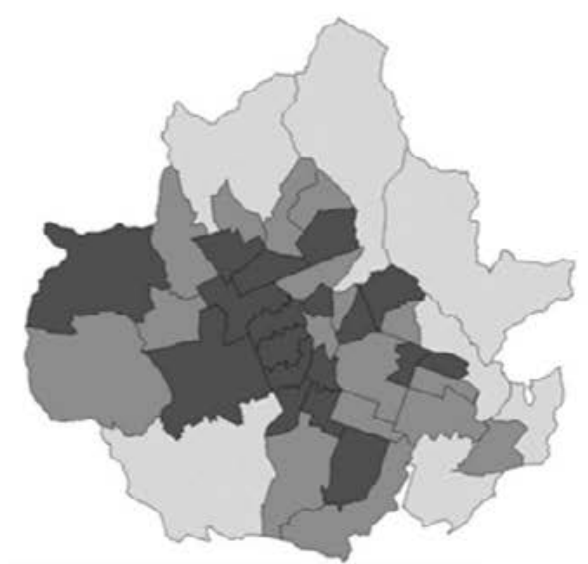

(c) Suwon

(d) Seongnam
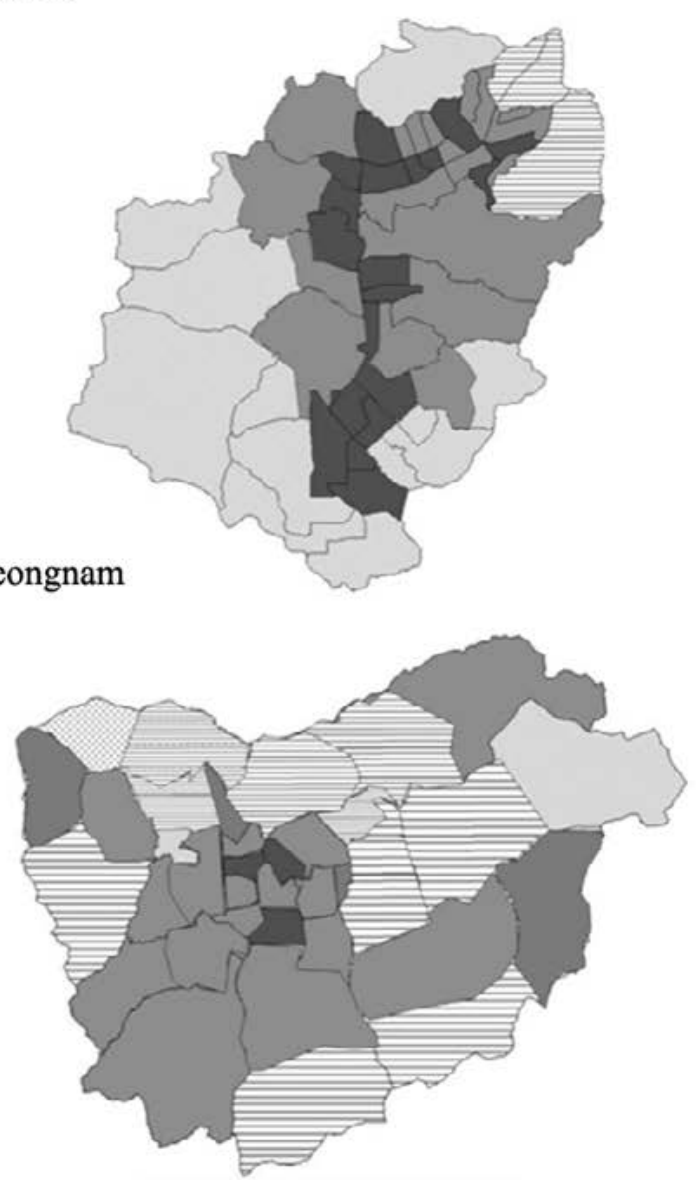

(e) Uijeongbu

FIGURE 3. Spatial Distribution of TTTDOCO for Each City 


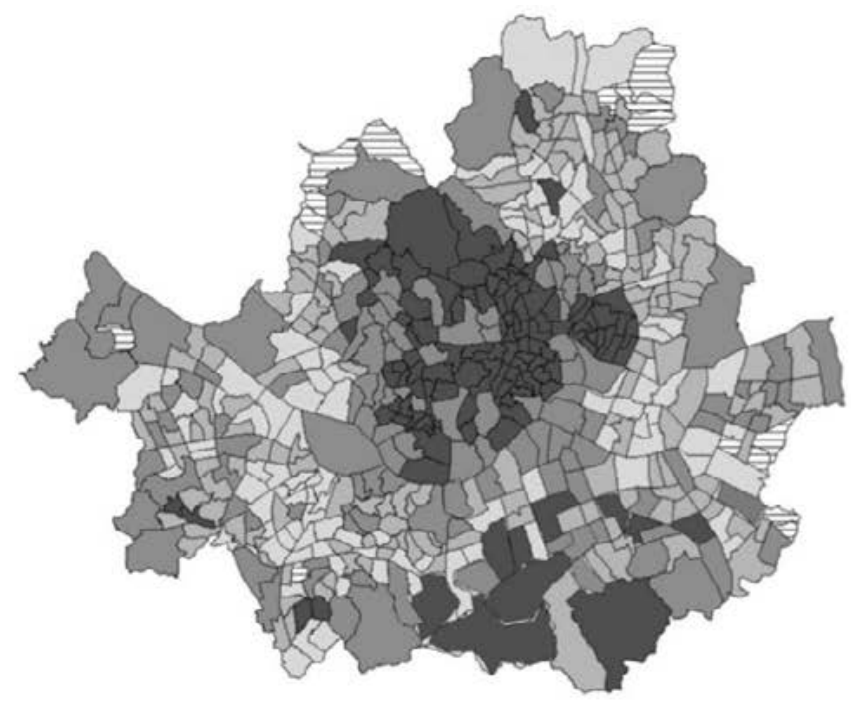

(a) Seoul

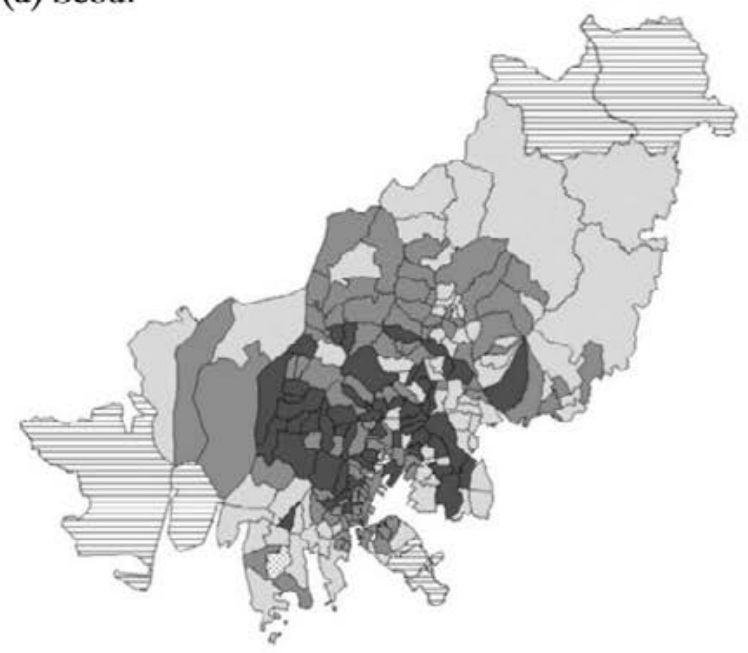

(b) Busan

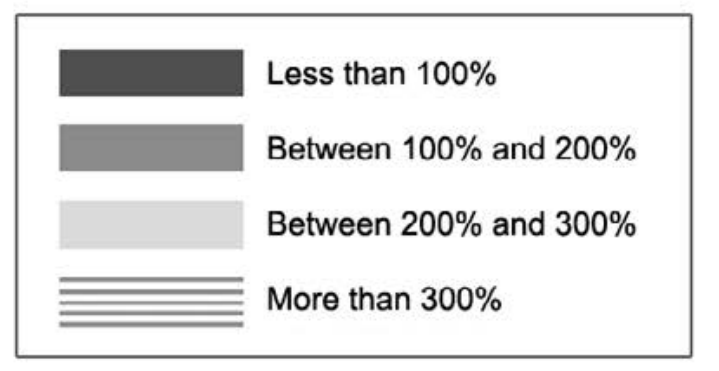

FIGURE 4. Spatial Distribution of TTTDOCI for Each City

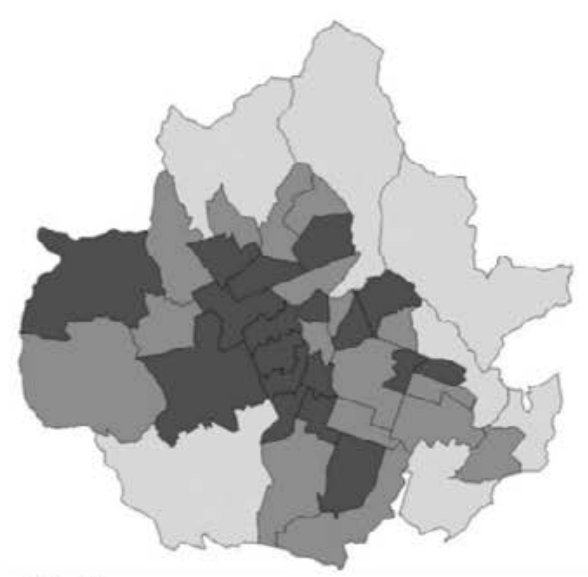

(c) Suwon

(d) Seongnam
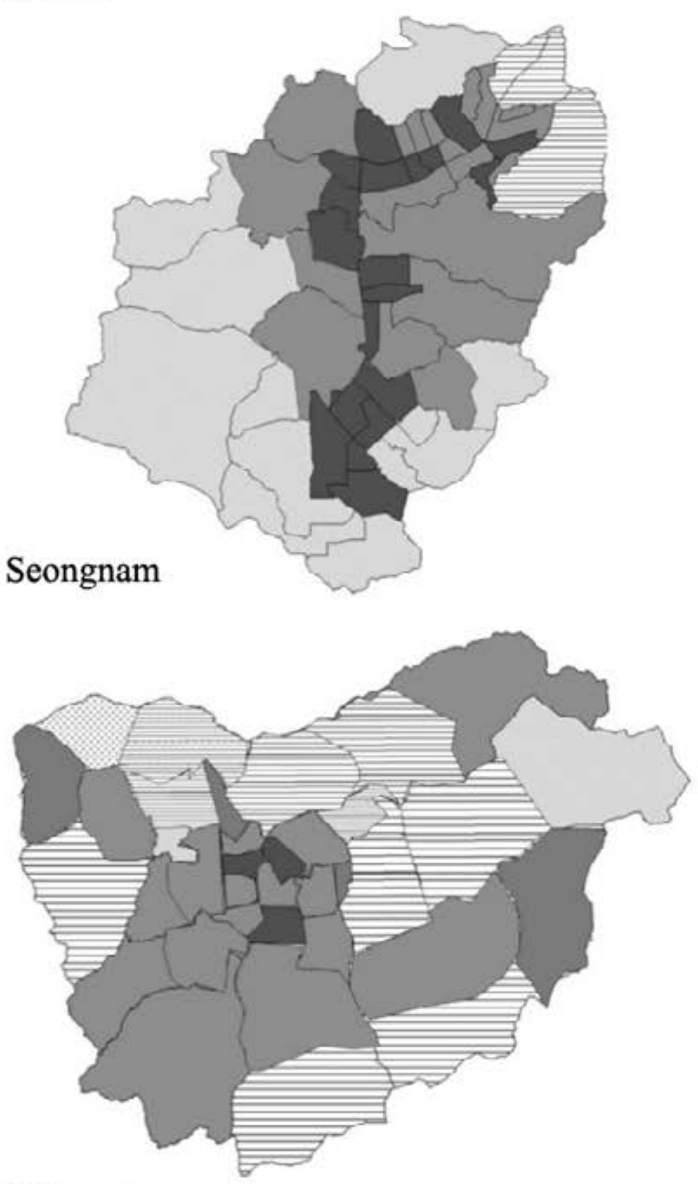

(e) Uijeongbu 


\section{Conclusion}

Using Lee's previously-developed measures to indicate the competitiveness and indirectness of a transit system (2008), this paper evaluated the transit network of five major cities in Korea and developed a geographical presentation method.

The shape of a transit network is usually affected by demand size; similarly, the shape of a transit network also affects transit demand size. Therefore, the relationship between the shape of a transit network and demand size is complicated but is worth investigating. Indeed, many other factors affect transit demand, so it may not be appropriate to connect transit network directness and transit demand size. However, as discussed, transit travel time is an important factor for mode choice, so it is still meaningful to find the relationship between transit demand size and transit network directness.

Although the results of the analysis and geographical presentation are for five specific cities, the developed methodology can be used to analyze any cities and their transit networks. Transit agencies can have a better visual understanding of their transit network directness and can improve transit network configuration where transit network directness is poor.

The analysis of the five cities shows some meaningful results that may be generalized and used for other cities as well. First, most transit ridership (transit demand/population) depends on transit network directness. Second, to attract more transit riders, the weighted averages of the transit network directness measures should be meaningfully lower than the simple averages of the transit network directness. That means transit routes must be more direct where large transit demands exist. Third, a transit network is more direct in cities with higher population densities.

This research provided valuable illustrations (Figures 2-4) of transit network directness. Figures 3 and 4 show the spatial distribution of zones that have different categories of transit service in terms of competitiveness and directness. From those figures, it is clear that Busan provides very poor service in the outer part of the city, and no zone in Suwon has more than $300 \%$ of additional travel time by transit. These figures show which areas should be improved in terms of directness of transit service.

The measures and concepts discussed in this paper rely on the first author's previous research, but this paper systematically structures and mathematically develops them in detail so they can be useful for transit network design and planning. Indeed, this analysis provides a good guideline to evaluate which cities need to improve their transit network to provide more direct service and also provides a good geographical guideline of which areas need to be improved in terms of the directness of the transit service, although transit network directness may result from many other concerns, such as social issues, politics, topology, and the original transit network that the existing users are used to.

For future research, if many different cities with good transit networks are analyzed using these measures, it will be possible to provide a guideline for proper transit network directness for cities of different size. Also, the relationship between transit network directness and land use patterns or topology will be worth investigating. 


\section{Acknowledgment}

This research was supported by a National Research Foundation of Korea (NRF) grant funded by the Korean government (MSIP) (NRF-2010-0029446) and the National Transportation Center at Morgan State University.

\section{References}

Ballou, R. H., H. Rahardja, and N. Sakai. 2002. "Selected Country Circuity Factors for Road Travel Distance Estimation." Transportation Research Part A: Policy and Practice, 36(9): 843-848.

Barthlemy, M. 2011. "Spatial Networks." Physics Reports, 499(13): 1-101.

Berkow, M., A. M. El-Geneidy, R. L. Bertini, and D. Crout. 2009. "Beyond Generating Transit Performance Measures.” Transportation Research Record, 2111(1): 158-168.

Bertini, R. L., and A. El-Geneidy. 2003. "Using Archived Data to Generate Transit Performance Measures." Transportation Research Record, 1841: 109-119.

Cambridge Systematics and Economic Development Research Group. 1999. "Public Transportation and the Nation's Economy: A Quantitative Analysis of Public Transportation's Economic Impact." Prepared for the Private Sector Business Members of the American Public Transit Association, Washington, DC.

Cedar, A., and Y. Israeli. 1998. "User and Operator Perspective in Transit Network Design."77th Annual Meeting of the Transportation Research Board, Paper No. 980267.

Dantzig, G. B. 1966. "All Shortest Routes in a Graph. Théorie Des Graphes." Proceedings of the International Symposium, Rome.

Dijkstra, E. W. 1959. "A Note on Two Problems in Connection with Graphs." Numerische Mathematik, 1: 269-271.

Fan, W,. and R. B. Machemehl. 2004. "Optimal Transit Route Network Design Problem: Algorithms, Implementations, and Numerical Results." Center for Transportation Research, University of Texas, Austin.

Guihaire, Valerie, and Jin-Kao Hao. 2008. "Transit Network Design and Scheduling: A Global Review." Transportation Research Part A, 42(10): 1251-1273.

Lee, Young-Jae. 1998. "Analysis and Optimization of Transit Network Design with Integrated Routing and Scheduling." Ph.D. dissertation, University of Pennsylvania, Philadelphia.

Lee, Young-Jae. 2006. "Transit Network Sensitivity Analysis." Journal of Public Transportation, 9(1): 21-52.

Lee, Young-Jae. 2008. "Comparative Measures for Transit Network Performance Analysis." Journal of the Transportation Research Forum, 47(3), Special Transit Issue. 
Lee, Young-Jae, and V. R. Vuchic. 2005. "Transit Network Design with Variable Demand." Journal of Transportation Engineering, 131(1): 1-10.

McGillivray, Robert G. 1970. "Demand and Choice Models of Modal Split." Journal of Transport Economics and Policy: 192-207.

Moore, E. F. 1957. "The Shortest Path Through a Maze." Proceedings of an International Symposium on the Theory of Switching, Part II: 285-292.

Newell, G. F. 1980. Traffic Flow on Transportation Networks. Massachusetts Institute of Technology Press.

Pattnaik, S. B., S. Mohan, and V. M. Tom. 1998. “Urban Bus Transit Route Network Design using Genetic Algorithm." Journal of Transportation Engineering, 124 (4):368-375.

Racca, David P., and Edward C. Ratledge. 2004. "Project Report for Factors that Affect and/ or Can Alter Mode Choice." Center for Demography and Survey Research, University of Delaware.

Ramirez, A., and P. Seneviratne. 1996. "Transit Route Design Applications Using Geographic Information Systems." Transportation Research Record, 1557: 123-139.

Spiess, Heinz, and Michael Florian. 1989. "Optimal Strategies: A New Assignment Model for Transit Networks." Transportation Research Part B, 23B(2): 83-102.

Transit Cooperative Research Program. 2003. “A Guidebook for Developing a Transit Performance-Measurement System." TCRP Report 88, Washington, DC.

Vuchic, V. R., et al. 1976. Transit Operating Manual. Pennsylvania Department of Transportation, University of Pennsylvania, Philadelphia.

Walk Score. www.walkscore.com/methodology.shtml, accessed July 25, 2014.

\section{About the Authors}

Young-JAe LeE, Ph.D. (YoungJae.Lee@morgan.edu) is an Associate Professor in the Department of Transportation and Urban Infrastructure Studies at Morgan State University in Baltimore, Maryland. He received B.S. and M.S. degrees at Seoul National University Korea as well as M.S. and Ph.D. degrees at The University of Pennsylvania. His main research focus is the improvement of transit systems, and he has conducted research projects and published papers on improving public transportation systems, including network design, operational efficiency, and ITS application for public transportation.

JUNG YoON CHOI (cjungy@ajou.ac.kr) received B.S. and M.S. degrees in transportation systems engineering from Ajou University in South Korea in 2010 and 2012, respectively. He currently is a Ph.D. Candidate in Transportation Systems Engineering at Ajou University, with doctoral work focused on the optimization of public transportation networks in terms of social welfare and equity. His research interests also include behavioral economics, transportation psychology, and the data-driven analysis of transportation network dynamics.

JeONG WHON YU, Ph.D. (jeongwhon@ajou.ac.kr) received B.S. and M.S. degrees in civil engineering from Seoul National University in South Korea in 1991 and 1993 and a Ph.D. 
degree in civil engineering from Purdue University in 2002. He is a Professor of Transportation Systems Engineering at Ajou University in Suwon, South Korea, and was a Research Associate at the Korea Transport Institute. His research interests include the use of econometrics, operations research, and computational intelligence techniques to model and evaluate the dynamics of transportation networks at both the micro and macro level, especially in the context of human behavior and advanced information systems. His Ph.D. dissertation received the 2002 Eric Pas Best Dissertation Award from the International Association for Travel Behavior Research.

KeECHOO CHOI, Ph.D. (keechoo@ajou.ac.k) is a Professor of Transportation and Director of the National Engineering Research Center (ERC) of Sustainable Transportation at Ajou University in Suwon, Korea. He holds B.S. and M.S. degrees in Civil Engineering from Seoul National University and a Ph.D. from the University of Illinois. His specialties include travel demand forecasting, ATIS type ITS, sustainable transportation with environmental concerns, and public transportation. He is the founding and managing editor of the International Journal of Sustainable Transportation, and his current research includes efficient transfer systems of transportation. 